\title{
Investigation of Oxidation-Reduction Properties of Growing Mediums for Cell Culture of Mammals under the Effect of Cosmo-Geophysical Factors
}

\author{
S. S. Moisa1, V. V. Tsetlin' ${ }^{1}$, A. N. Velikanov ${ }^{2}$ \\ ${ }^{1}$ Federal State-Financed Establishment of Science, State Scientific Center of Russian Federation, Institute of Biomedical \\ Problems of the Russian Academy of Sciences, Moscow, Russia; ${ }^{2}$ Moscow State University, Moscow, Russia
}

Correspondence to: A. N. Velikanov, butalana07@list.ru

Keywords: Cosmo-Geophysical Factors, Growing Mediums for Cell Culture of Mammals, Oxidation-Reduction Properties

Received: January 17, 2019 Accepted: February 18, $2019 \quad$ Published: February 21, 2019

Copyright $\odot 2019$ by authors and Scientific Research Publishing Inc.

This work is licensed under the Creative Commons Attribution International License (CC BY 4.0).

http://creativecommons.org/licenses/by/4.0/

\section{(c) (1) Open Access}

\section{ABSTRACT}

In model experiments were studied the effect of cosmo-geophysical factors of environment (hypomagnetic conditions during 2 days $\approx 1 \mathrm{mkT}$; electromagnetic irradiation (10 min - 2 $\mathrm{MHz}$ with amplitude $5 \mathrm{~V} / \mathrm{m}$ and power $30 \mathrm{mkVt}$, background $2-4 \mathrm{mkVt}$ ), $\gamma$-quantum (10 min-from the source ${ }^{137} \mathrm{Cs}$ ) and its combined effect on the physic-chemical properties (ORP and $\mathrm{pH}$ ) of growing medium for cell culture of mammals as nutrition medium 199 (PanEco, Russia). It was used a clear solution of medium (solution 1) and with the adding of $10 \%$ embryo bull serum-model of bio-medium (solution 2). Hypomagnetic conditions evoked the decreasing of ORP and $\mathrm{pH}$ value in both solutions, electromagnetic irradiation in the solution 1 which evoked the decreasing of ORP and the increasing of $\mathrm{pH}$ value, and in the solution 2 , on the contrary, the increasing of ORP with the unchanging $\mathrm{pH}$ value. $\gamma$-radiation sharply decreased ORP value and didn't change $\mathrm{pH}$ in solution 1 , i.e. the reduction properties increased. There is insignificant increasing of ORP value and the decreasing of $\mathrm{pH}$ is noted in the solution 2, that it is characterized with the increasing of oxidative properties of solution. Under the combined effect of hypomagnetic conditions and electromagnetic irradiation, the values of investigating parameters in the solution 1 decreased and in the solution 2 increased. It was observed acute decreasing of ORP value in both solutions under the combined effect of hypomagnetic conditions and $\gamma$-radiation, i.e. the reductive properties of the solutions increased sharply. In this the concentration $\mathrm{H}+$ significantly decreased, $(p<0.05)$. Combined effect of hypomagnetic conditions, electromagnetic irradiation and $\gamma$-radiation led to the decreasing of ORP and $\mathrm{pH}$ values in both solutions. Thus, the studying factors significantly change the oxidation-reduction properties of growing me- 


\section{diums. The investigation of the processes in biological mediums plays the important role in the assessment of environment effect during the flight in inter-planet space.}

\section{INTRODUCTION}

Effect of surrounding near-Earth space on biological objects changes in essential manner, it must inevitably accompany with the alteration of inner medium of bio-objects which basis consists of water. In model experiments we have established [1-6] the changing of water oxidation-reduction properties under the effect of environment factors (electromagnetic background, ionized radiation (IR), hypomagnetic field (HMF), volcano eruption and Sun eclipse). It is well-known that the concentration of water molecules in cells exceeds in 2 - 3 sequence, the concentration of protein and other molecules in cytoplasm. Water is capable to reflex the outer factors of effect in their structural changing, which renders accordingly immediate influence on physiological processes in organism.

Effect of environment factors on biological mediums is little studying. Proceeding from foregoing notions, it was logically to investigate, how the properties of inner water medium will change under the influence of characteristic for space flight low doses of IR, electromagnetic high frequency, electromagnetic super-high frequency and other factors of cosmic space-hypomagnetic field and also their combined effect. Besides that, it isn't elucidated the question about the effect on organism and, in particular, on the cell culture, the changing inner medium of habitat due to these factors. For more deep understanding of the mechanism of effect of cosmo-geophysical factors on living systems, it should pay attention to the investigation of physical properties of inner water medium. In this connection the interest represents the studying of such properties as oxidation-reduction potential (ORP) and hydrogen parameter ( $\mathrm{pH}$ ). As A.-L. Lavuazje considered, "life is a continuous circuit of oxidation-reduction processes", occurring in organism. The integrative parameter of these processes is the value of ORP of biological mediums of organism (blood, blood plasma, blood serum, urine, spinal cord liquor and others) [7]. According to I.M. Bahir's opinion, ORP should consider as homeostatic character of biological mediums of organism [8].

First attempts of ORP measuring in biological medium of man began still in 1930-th years [9, 10]. However, correlation ORP with some biochemical parameters was found only in the end of 60-th years last century [14]. A search keeps on even now. At present the correlation between ORP and LPO [11-13], ORP and antioxidant activity in blood serum [14] was established, it is found the inter-correlation ORP value with man's age [15], hypo- and hyperthyroidism [16], oncologic diseases [17], tuberculosis [17], infection diseases [18], hemorrhagic shock [19, 20], neuro-trauma [7], multi-organ deficiency [21], fulfilling the operation of coronary bypass surgery [22], the therapy with the treatment of hyperbaric oxygenation [23].

However, it should be noted that there are some difficulties during the carrying out of ORP measuring in biological mediums due to electrochemical method. These difficulties are connected with the fact that in oxidation-reduction systems it is necessary to take into account not only the oxidation-reduction properties of the investigating medium, but and the state of electrode surface [24]. Given this, we considered it is expedient to fulfill the investigations on the model of biological medium.

As I.M. Sechenov noted, "organism without outer environment, supporting its state, is unfeasible", that's why in scientific determination of organism ought to include the environment, effecting on it [25]. In this, the interest evokes that fact, how the state of inner water medium, undergoing to the effect of cosmo-geophysical factors of environment, will change and, how this changing state reflexes on the living organisms. The growing medium for cell culture of mammals (model of bio-medium) was selected as the objects of investigation. The aim of these studying was to investigate the influence of low doses of radiation, electromagnetic irradiation high (EMI HRR) and super-high radio-range (EMI SHRR), a 40-fold attenuated geomagnetic field and their combined effect on the reaction of the model of bio-medium.

\section{METHODS}

In model experiments were studied the effect of cosmo-geophysical factors of environment (hypo- 
magnetic conditions during 2 days (HMC) $\sim 1 \mathrm{mkT}$; electromagnetic irradiation (EMI) $10 \mathrm{~min}-2 \mathrm{MHz}$ with amplitude $5 \mathrm{~V} / \mathrm{m}$ and power $30 \mathrm{mkVt}$, background $2-4 \mathrm{mkVt}, \gamma$-quantum $(10 \mathrm{~min}$ - from the source ${ }^{137} \mathrm{Cs}$ ) and its combined effect on the physic-chemical properties (ORP and $\mathrm{pH}$ ) of growing medium for cell culture of mammals as nutrition medium 199 (PanEco, Russia) in two variations: clear solution of medium (solution 1) and with the adding of $10 \%$ embryo bull serum, it represents the model of inner medium of living organism model of bio-medium (solution 2). ORP and $\mathrm{pH}$ measurement were carried out using ionomer I-160MI.

Eight groups of experiments were carried out. In the 1-st group the effect of low doses (>10 sGy) of ionized radiation (IR) was studying under the effect of $\gamma$-quantum $\left({ }^{137} \mathrm{Cs}\right.$, the dose power $-690 \mathrm{mkGy} / \mathrm{h}$, the time of exposition $-10 \mathrm{~min}$ ) on the value of ORP and $\mathrm{pH}$ of solutions 1 and 2. Nature radiation background during the fulfilling of experiments was $37 \mathrm{mkRh} / \mathrm{h}$. In the 2 -nd group the effect of a 40 -fold attenuated geomagnetic field ( $\sim 1 \mathrm{mkT}$, that conforms to the induction level of magnetic field on Moon surface) on the value of studying parameters of solutions were investigated. The samples of solutions were put in hypomagnetic chamber (HMC) - the device "Screen ferromagnetic", produced in Zelenograd, Moscow region, which represented a cylinder, making from 15 lays of permaloj, inner diameter $=110 \mathrm{~mm}, \mathrm{~L}=500$ $\mathrm{mm}$. In the 3-rd group the effect of combined action of IR in low doses ( $\gamma$-irradiation) and HMC on the value of ORP and $\mathrm{pH}$ was studied. Two samples of solutions (in which preliminary were measured the $\mathrm{ORP}$ and $\mathrm{pH}$ value) were taken. The second samples of solutions were undergone to the irradiation with $\gamma$-quantum, the time of exposition-10 min, the first samples served as control. After that all samples were put in HMC for 2 days. In 2 days the value of ORP and $\mathrm{pH}$ in investigating samples were determined at once. In the 4-th group the effect of EMI HRR and SHRR (frequency $2 \mathrm{MHz}$, amplitude $5 \mathrm{~V} / \mathrm{m}$, power 30 $\mathrm{mkW}$, background $4 \mathrm{mkW}$ ) on the values of ORP and $\mathrm{pH}$ was investigated. The time of exposition was 10 min. In the 5-th group combined effect of EMI and HMC on the solutions was studied. The samples of solutions, undergoing to the EMI action, were put for 2 days in HMC. After that the samples were derived from HMC and determined ORP and $\mathrm{pH}$. Combined effect of HMC, EMI and $\gamma$-quantum was studied in the 6-th group. The samples of solutions consequently underwent to the effect of EMI, $\gamma$-quantum (analogically 1 and 4 groups) and put in HMC for 2 days. In 2 days the ORP and $\mathrm{pH}$ values were measured in investigated samples. The effect of combined action of IR and EMI on the values of ORP and pH was studied in the 7-th group. The measurements of ORP and $\mathrm{pH}$ in the investigating solutions in geomagnetic conditions were served as control (the 8 -th group).

\section{RESULTS AND DISCUSSION}

The results of investigations are represented in Tables 1-3.

Table 1. Dynamics of ORP and $\mathrm{pH}$ values of nutritional mediums 199 for cell cultures of mammals under the effect of cosmo-geophysical factors.

\begin{tabular}{ccc}
\hline Conditions of experiment & \multicolumn{2}{c}{ Parameters } \\
\cline { 2 - 3 } Geomagnetic conditions & $\mathrm{ORP}, \mathrm{mV}$ & $\mathrm{pH}$ \\
\hline Hypomagnetic conditions (HMC) & 160 & 6.3 \\
Electromagnetic irradiation (EMI) & 110 & 6.8 \\
$\gamma$-quantum & $125_{\text {initial }}-90_{\text {EMI }}$ & $7.25_{\text {initial }}-7.6_{\text {EMI }}$ \\
EMI + $\gamma$-quantum & $180_{\text {initial }}-91_{\gamma \text {-quantum }}$ & $7.3_{\text {initial }}-7.34_{\gamma \text {-quantum }}$ \\
HMC + EMI & 75 & 7.0 \\
HMC + $\gamma$-quantum & 66 & 6.8 \\
HMC + EMI + $\gamma$-quantum & 25.8 & 8.8 \\
\hline
\end{tabular}


Table 2. Dynamics of ORP and $\mathrm{pH}$ values of nutritional mediums 199 with adding of $10 \%$ embryo bull serum for cell cultures of mammals (model of bio-medium) under the effect of cosmo-geophysical factors.

\begin{tabular}{ccc}
\hline \multirow{2}{*}{ Conditions of experiment } & \multicolumn{2}{c}{ Parameters } \\
\cline { 2 - 3 } Geomagnetic conditions & ORP, $\mathrm{mV}$ & $\mathrm{pH}$ \\
HMC & 100 & 7.7 \\
EMI & 73 & 7.3 \\
$\gamma$-quantum & 131 & 7.35 \\
EMI + $\gamma$-quantum & 71 & 7.34 \\
HMC + EMI & 118 & 7.3 \\
HMC + $\gamma$-quantum & 94 & 7.92 \\
HMC + EMI + $\gamma$-quantum & -228 & 7.42 \\
\hline
\end{tabular}

Table 3. Comparison of dynamics of ORP and $\mathrm{pH}$ values of investigating solutions.

\begin{tabular}{ccccc}
\hline \multirow{2}{*}{ Conditions of experiment } & \multicolumn{4}{c}{ Parameters } \\
\cline { 2 - 5 } & ORP, $\mathrm{mV}$ & $\mathrm{pH}$ & ORP, $\mathrm{mV}$ & $\mathrm{pH}$ \\
\cline { 2 - 5 } Solution 1 & 100 & 7.7 \\
Geomagnetic conditions & 160 & 8.3 & 73 & 7.3 \\
HMC & 110 & 6.8 & 131 & 7.35 \\
EMI & 90 & 7.6 & 71 & 7.34 \\
$\gamma$-quantum & 91 & 7.34 & 118 & 7.3 \\
EMI + $\gamma$-quantum & 75 & 7.0 & 94 & 7.92 \\
HMC + EMI & 66 & 6.8 & -228 & 7.42 \\
HMC + $\gamma$-quantum & 25.8 & 8.8 & 113 & 6.9 \\
\hline HMC + EMI + $\gamma$-quantum & 86 & 5.66 & & \\
\hline
\end{tabular}

It is already noted the difference in initial meaning of values of studying parameters of solutions in geomagnetic conditions. So, in solution $1 \mathrm{ORP}$ value $=160 \mathrm{mV}, \mathrm{pH}=8.3$, and in solution 2, correspondingly, $\mathrm{ORP}=100 \mathrm{mV}, \mathrm{pH}=7.7$. In our opinion, these differences explain by the fact, that water molecules, which connected with negative charged protein molecules in solution 2, possess higher electron emission, i.e. protein molecules are capable easily to give up electrons in medium. In the result ORP value falls due to the larger formation of dissociato water molecules. In this the concentration $\mathrm{H}+$ increases and $\mathrm{pH}$ value falls.

$H M C$ rendered the same effect for the two medium solutions-the decreasing of ORP and $\mathrm{pH}$ values, that testifies about the changing of energy state, mainly water molecules and their quantity.

$E M I$ in the solution 1 evoked the decreasing of ORP value and the increasing $\mathrm{pH}$ value, i.e. the recombination of ions $\mathrm{H}^{+}$and $\mathrm{OH}^{-}$or capture of ions by biological components of medium. The decreasing of ORP value is connected with the activation of water molecules, but the increasing of $\mathrm{pH}$ value-the result of the dissociation of activated water molecules [26]. Another data was noted in the solution 2: the 
increasing of ORP value with the unchanging $\mathrm{pH}$ value, it, apparently, is connected with the stabilization properties of organic components of the solution.

$\gamma$-quantum provoked abrupt decreasing of ORP value (for 50\%) and didn't change $\mathrm{pH}$ in the solution 1 , i.e. the reduction properties increased. There is insignificant increasing of ORP value and the decreasing of $\mathrm{pH}$ is noted in the solution 2, that it is characterized with the increasing of oxidation properties of solution.

Under combined effect of EMI and $\gamma$-quantum, the values of ORP and $\mathrm{pH}$ in the solution 1 decreased yet more in comparison with the effect of each separate factor. So, ORP $=75 \mathrm{mV}, \mathrm{pH}=7.0$. At the same time in the solution $2 \mathrm{ORP}$ value increases and $\mathrm{pH}$ value practically is changed slightly $(\mathrm{ORP}=118 \mathrm{mV}$, $\mathrm{pH}=7.3)$.

Under combined influence of HMC and EMI, the values of investigating parameters in the solution 1 decreased, it could mean the decreasing of work of electron's exit from water or the components of medium. In the solution 2, on the contrary, the increasing of these parameters was noted, that characterizes the intensification of electron link with water molecules or the components of the solution and also with the increasing of work of electron's exit.

The special interest provoked the data of combined effect of HMC and $\gamma$-quantum, in which ORP value decreases sharply (in the solution 1-from $91 \mathrm{mV}$ of initial level to $25.8 \mathrm{mV}$ after the effect, in the solution 2-from $71 \mathrm{mV}$ of initial meaning to $-228 \mathrm{mV}$ ), i.e. the reduction properties of the solution increase sharply, that, probably, it is connected with the interrelation of components of the solution. In this the concentration $\mathrm{H}^{+}$significantly decreases.

Combined effect of HMC, EMI and $\gamma$-quantum led to the decreasing of ORP and $\mathrm{pH}$ values in both solutions. It testifies, apparently, about the passing of complex chemical reactions. Receiving data allow concluding that the investigating cosmo-geophysical factors can significantly change the oxidation-reduction properties of growing mediums.

Further investigations will show, how the state of growing mediums, undergoing to the influence of studying factors, will declare on the growth of cell cultures of mammals. The investigation of the processes in biological mediums plays the important role in the assessment of environment effect during the flight in inter-planet space.

\section{CONFLICTS OF INTEREST}

The authors declare no conflicts of interest regarding the publication of this paper.

\section{REFERENCES}

1. Moisa, S.S., Zotin, A.A. and Tsetlin, V.V. (2015) The Embryonic Development of Great Ramshorn Planorbarius Corneus under the Hypomagnetic Field. American Journal of Life Sciences, 3, 25-31. https://doi.org/10.11648/j.ajls.s.2015030102.15

2. Tsetlin, V.V., Zotin, A.A. and Moisa, S.S. (2014) Effect of the Alteration of Magnetic Field on the Development of Great Ramshorn Planorbarius corneus (GASTROPODA, PLANORBIDAE). Aviakosmicheskaia i ekologicheskaia meditsina = Aerospace and Environmental Medicine, 48, 36-44.

3. Tsetlin, V.V. (2010) Investigation of Water Reaction on the Variations of Cosmo-Physical and Geo-Physical Factors on the Environment Space. Aviakosmicheskaia i ekologicheskaia meditsina = Aerospace and Environmental Medicine, 44, 26-31.

4. Tsetlin, V.V. and Fineshtein, G.S. (2012) About the Influence of Cosmo-Physical, Geo-Physical and Radiation Factors on Electro-Physical and Biological Properties of Water. Metaphysics, 2, 81-99.

5. Tsetlin, V.V., Moisa, S.S., Levinskikh, M.A. and Nefedova, E.L. (2016) Effects of Very Small Doses of Ionizing Radiation and Hypomagnetic Field Change Physiological Characteristics of Higher Plant Seeds. Aviakosmicheskaia i ekologicheskaia meditsina = Aerospace and Environmental Medicine, 50, 51-58. 
https://doi.org/10.21687/0233-528X-2016-50-6-51-58

6. Moisa, S.S., Tsetlin, V.V., Levinskikh, M.A. and Nefedova, E.L. (2016) Low Doses of Ionized Radiation and Hypomagnetic Field Alter Redox Properties of Water and Physiological Characteristics of Seeds of the Highest Plants. Journal of Biomedical Science and Engineering, 9, 410-418. https://doi.org/10.4236/jbise.2016.98036

7. Rael, L., Bar-Or., Mains, C., et al. (2009) Plasma Oxidation-Reduction Potential and Protein Oxidation in Traumatic Brain Injury. Journal of Neurotrauma, 26, 1203-1211. https://doi.org/10.1089/neu.2008.0816

8. Bahir, I.M. (1999) Determination of Terms "Water" and "Solution" According to the Technology of Electrochemical Activation. Electrochemical Activation in Medicine, Agriculture, Industry, 14, 41-47.

9. Bembe, C. and Dietrich, S. (1941) Zur Messung oxydoreductiver Potentiale im Blut. Zeitschrift für Die Gesamte Experimentelle Medizin, 109, 546-565. https://doi.org/10.1007/BF02611511

10. Waterman, N. (1933) Ueber Aenderungen des Redoxpotentials im Serum durch Röntgenbestrahlung. Zeitschrift für Krebsforschung, 38, 301-311. https://doi.org/10.1007/BF01619931

11. Kolls, J. (2006) Oxidative Stress in Sepsis: A Redox. Journal of Clinical Investigation, 116, 860-863. https://doi.org/10.1172/JCI28111

12. Margină, D., Grădinaru, D. and Mitrea, N. (2009) Development of a Potentiometric Method for the Evaluation of Redox Status in Human Serum. Revue Roumaine de Chimie, 54, 45-48.

13. Rael, L., Bar-Or., Salottolo, K., et al. (2009) Injury Severity and Serum Amyloid. A Correlate with Plasma Oxidation-Reduction Potential in Multitrauma Patients: A Retrospective Analysis. Scandinavian Journal of Trauma, Resuscitation and Emergency Medicine, 17, 57. https://doi.org/10.1186/1757-7241-17-57

14. Andreev, V.N., Evseev, A.K., Garaeva, G.R. and Goldin, M.M. (2013) Comparison of Redox-Potential and Antioxidant Activity of Blood Serum. Molecular Medicine, 4, 37-40.

15. Van Rossum, J. and Schamhart, D. (1991) Oxidation-Reduction (Redox) Potentiometry in Blood in Geriatric Conditions: A Pilot Study. Experimental Gerontology, 26, 37-43. https://doi.org/10.1016/0531-5565(91)90060-Y

16. Marmasse, C. and Grosz, H. (1964) Direct Experimental Evidence of a Functionally Active Electron Transport System in Human Blood. Nature, 202, 94. https://doi.org/10.1038/202094a0

17. Ziegler, E. (1965) The Redox Potential of the Blood in Vivo and in Vitro. Charles C. Thomas Publisher, Springfield, 196.

18. Dzhikiia, I.V., Rizhvadze, M.A. and Dzhangidze, M.A. (2006) Oxidation-Reduction Potential of Blood and System of under Cytomegalovirus Infection in Pregnant. Georgian Medical News, 5, 28-31.

19. Serov, V.I. (1994) Alteration of Blood Flow, Tension and Diffusion of Oxygen, Oxidation-Reduction Potential in Brain Cortex under Hemorrhagic Shock and Hyperbaric Oxygenation. Bulletin Hyperbaric Biology and Medicine, 2, 5-9.

20. White, N., Collinson, M., Boe, R., et al. (2008) Redox Monitoring Reveals Increased Susceptibility of Whole Blood to Oxidative Stress during Hemorrhagic Shock. Circulation, 18, S1488.

21. Taniguchi, S., Kodama, K., Matsuyama, H., et al. (1987) Contribution of Arterial Redox Potential Measurement to the Care of Critically Ill Patients. Journal of Anesthesia, 1, 125-131. https://doi.org/10.1007/s0054070010125

22. Rae, S., Palazzo, R., Metz, H., et al. (1997) Redox Potential Measurements of Plasma in Patients Undergoing Coronary Artery Bypass Graft and Its Clinical Significance. Journal of Pharmacological and Toxicological Methods, 38, 151-156. https://doi.org/10.1016/S1056-8719(97)00080-4

23. Goldin, M.M., Romasenko, M.V., Evseev, A.K., Levina, O.A., Petrikov, S.S., Aleschenko, E.I. and Krylov, V.V. (2010) Assessment of Efficiency of Hyperbaric Oxygenation Using under the Acute Cerebral Pathology with Help of Electrochemical Method. Neurosurgery, 4, 33-39. 
24. Mikhaelis, L. (1932) Oxidation-Reduction Potentials and Their Physiological Meaning. Skadovsky, S.N. State Chemistry Technological Institute, Moscow, 160.

25. Sechenov, I.M., Pavlov, I.P. and Vvedensky, N.E. (1952) Physiology of Nerve System. Select Works. Issue 1, Bykov, K.M. Medgiz, Moscow, 157.

26. Rassadkin, V.P. (2008) Usual and Unusual Water. Gallery STO, Moscow, 840. 